\title{
Editorial
}

\section{Place branding in Africa}

Place Branding and Public Diplomacy (2014) 10, 32-34. doi:10.1057/pb.2013.31

Africa is the world's second largest and second most populated continent after Asia. It has a diverse geography and climate. Africa's climate varies from Mediterranean along the Northern coast, to desert in the Southeast and North, to a tropical climate in Central and Western parts and even subarctic conditions in its highest mountain areas.

Africa is also a resource-rich continent. It has oil, minerals, timber, wildlife, water and a rich soil for agriculture. The continent nurtured the first homo sapiens, and its resources have cared for existing and attracted new populations ever since. Present-day Africa is a patchwork of diversity with different indigenous cultures, habits and religions overlain by the languages and political boundaries imposed by European colonialism. UNESCO currently estimates that more than 2000 languages are spoken in Africa. This makes Africa the most multilingual continent in the world. It is not unusual for individuals to speak one or more of the local African languages in addition to one or more European languages.

Africa not only has an abundance of natural resources, it is also geographically rich. Africa includes more than 60 officially recognized UNESCO World Heritage sites, such as the pyramids of Egypt, the city of Timbuktu, the slave castles of Ghana, the monolithic churches at Lalibela in Ethiopia and the continent's network of national parks. The combination of sites and attractions makes Africa a very attractive place to visit.

Recent years have seen abatement in warfare, which plagued the continent in much of the post-colonial period, paralleled by an increased process of democratization. The associated stability has made Africa more attractive for investment. This, in turn, has led to an increased flow of money to the region, the emergence of a stronger middle class and an increase in competition among places. It is in this context that countries all over Africa have been making an effort to build their brands and to differentiate their offerings in order to attract tourists, investment and people.

At Place Branding and Public Diplomacy we were interested in furthering our collective understanding of place branding activities on this continent. I proposed a special issue inviting scholars and practitioners to submit articles to the journal in order to document place branding efforts conducted by different countries, regions and cities in Africa. This was an exciting project and we had high hopes at the beginning that there would be much interest and many cases of place branding activities being conducted in Africa.

Unfortunately, the result was disappointing.

First, the lack of submissions was surprising. Of the few articles received, only four were considered suitable for publication. This limited number of articles made it impossible to have a special issue entirely dedicated to place branding in Africa. Therefore, the four articles are incorporated into this regular issue of the journal.

Second, there was a specific absence of articles originating from Africa itself. Not one of the four articles selected for publication came from an African institution. Three articles were co-authored by African researchers who are based in Europe. 
I was especially disappointed that no article emerged from a South African university. South African universities enjoy greater resources than institutions in other African countries, and South Africa itself has great sophistication in the branding industry. Moreover, South Africa has a highly developed tourism industry and staged the 2010 FIFA World Cup in Football.

I took the opportunity to discuss this situation with several professors based at African universities. They suggested multiple reasons such as a lack of financing and poor academic resources - including poor Internet connections and limited access to international journals. In addition, it also became apparent through this process that place branding as a concept is not as well grasped as one might expect in Africa. The concept is not yet fully incorporated within either the research or political communities. Those of us who feel that Africa will benefit from thinking about branding need to host more events and conferences in Africa to promote place branding among local researchers, politicians and practitioners. It would also help to develop more collaborative projects and establish stronger relationships between universities in Africa and elsewhere in the world in the place branding field.

It is fundamental that local, regional and national politicians understand the concept of place branding in order to effectively promote their locations. These leaders need to understand that place branding requires more than the tactically driven application of advertising. It must be developed with a strategic outlook, including careful analysis of what the location wants to achieve and how it wants to be perceived in the long term. This is a matter of some urgency as Africa cannot afford to waste either money or time.

Nonetheless, it is worth mentioning that the four published articles are quite relevant to promote and further our knowledge in Place Branding. The four articles are conceptually and methodologically quite different from one another, which helps to enrich this journal edition.

One article is a case study written by Edson Santos and Dr Maria Campo on the process of developing the Cape Verde brand. Cape Verde is highly dependent on the tourism industry but lacked a strong brand identity that could incorporate the main differential attributes of the destination. The article is a critical analysis of the brand identity creation process. This process is not only interesting but also demonstrates the difficulties of developing a new brand identity for a country.

Another interesting and original case study by Dr Colin Alexander explores the use of government development assistance of Scotland, a sub-state, to Malawi. Scotland is using development aid to raise its 'profile as a nation during the debate over its' full independence from the United Kingdom. This article highlights the use of Public Diplomacy to fulfill different goals reaching distinct audiences.

Peter Harengel and Dr Ayantunji Gbadamosi's research focused on how South Sudan, a new country that emerged from the division of Sudan, is portrayed in the international media. Their research is based on ground theory, and the case is a unique opportunity to understand how international media wrote into existence this new nation.

The article is especially interesting as it analyses media from different countries. The authors then demonstrate how the cultural and the national context of each country's media influence the portrayal of South Sudan. This is a relevant issue for Place Branding as a sound brand strategy has to be developed while acknowledging the cultural and political context of the different target markets.

Lastly, an article from Fatimazohra El aouni, Dr Cascón-Pereira and Dr Hernández-Lara explores the relevance of emigrants on shaping the image of their country of origin. Their research is based in Spain and explores which brand elements Moroccan emigrants transmit in Spain. The relevance of the emigrants in the brand building process is an understudied aspect, and for this reason this article is quite valuable. The four articles are quite interesting and useful. There is no doubt that they help to further the understanding of the concept of Place Branding.

My hope is that by next time there is a special issue of place branding in Africa there will be many more article submissions and that the majority of 
these papers will be authored by researchers and practitioners based in Africa.

On a final note, I would like to extend a sincere thank you to all the people involved with this issue. This publication would not have been possible if it were not for the contribution of my colleagues in the place branding field. Thank you to all for your participation.

Joao Freire 